\title{
TU/e EnNHOUN

\section{Expanded comfort assessment in outdoor urban public spaces using Box-Cox transformation}

\section{Citation for published version (APA):}

Peng, Y., Feng, T., \& Timmermans, H. (2019). Expanded comfort assessment in outdoor urban public spaces using Box-Cox transformation. Landscape and Urban Planning, 190, [103594].

https://doi.org/10.1016/j.landurbplan.2019.103594

\section{Document license:}

TAVERNE

DOI:

10.1016/j.landurbplan.2019.103594

Document status and date:

Published: 01/10/2019

\section{Document Version:}

Publisher's PDF, also known as Version of Record (includes final page, issue and volume numbers)

\section{Please check the document version of this publication:}

- A submitted manuscript is the version of the article upon submission and before peer-review. There can be important differences between the submitted version and the official published version of record. People interested in the research are advised to contact the author for the final version of the publication, or visit the $\mathrm{DOI}$ to the publisher's website.

- The final author version and the galley proof are versions of the publication after peer review.

- The final published version features the final layout of the paper including the volume, issue and page numbers.

Link to publication

\section{General rights}

Copyright and moral rights for the publications made accessible in the public portal are retained by the authors and/or other copyright owners and it is a condition of accessing publications that users recognise and abide by the legal requirements associated with these rights.

- Users may download and print one copy of any publication from the public portal for the purpose of private study or research.

- You may not further distribute the material or use it for any profit-making activity or commercial gain

- You may freely distribute the URL identifying the publication in the public portal.

If the publication is distributed under the terms of Article 25fa of the Dutch Copyright Act, indicated by the "Taverne" license above, please follow below link for the End User Agreement:

www.tue.nl/taverne

Take down policy

If you believe that this document breaches copyright please contact us at:

openaccess@tue.nl

providing details and we will investigate your claim. 
Research Paper

\title{
Expanded comfort assessment in outdoor urban public spaces using Box-Cox transformation
}

\author{
Y. Peng ${ }^{\mathrm{a}}$, T. Feng ${ }^{\mathrm{a}, *, 1}$, H.J.P. Timmermans $\mathrm{s}^{\mathrm{a}, \mathrm{b}, 2}$ \\ ${ }^{a}$ Urban Planning Group, Department of the Built Environment, Eindhoven University of Technology, PO Box 513, 5600MB Eindhoven, The Netherlands \\ ${ }^{b}$ Department of Air Transportation Management, Nanjing University of Aeronautics and Astronautics, Jiangjun Avenue, Jiangning District, Nanjing 211106, China
}

\section{A R T I C L E I N F O}

\section{Keywords:}

Outdoor comfort

Expanded model

Non-linear model

Box-Cox transformation

\begin{abstract}
A B S T R A C T
In order to assess outdoor comfort of individuals, this paper discusses the results of an expanded non-linear model using Box-Cox transformation. Instead of thermal sensation, individuals' comfort assessment was used as the dependent variable. Further, a flexible non-linear model that allows for decreasing or increasing marginal effects of the explanatory variables on the ratings of outdoor comfort was specified. Apart from the physical microclimatic and environmental attributes, the variables related to the socio-demographics, emotional status, expectations, preference, perceptions and behavioral aspects were also incorporated in the model. To reduce the potential dependency of results on the sampled locations, a stated choice experiment was designed to systematically vary the conditions with different combinations of spatial attributes. The data was collected through a structured questionnaire and physical measurements of the surrounding environment from eight public spaces in Eindhoven, The Netherlands. Results show that the influence of non-physical factors, such as socio-demographics, behavioral and psychological attributes, on outdoor comfort are substantial and significant.
\end{abstract}

\section{Introduction}

Public open spaces play an important role in urban residents' daily life and contribute to the liveability and vitality of a city. Comfortable public spaces improve citizen's quality of life by accommodating encounters with fellow citizens, offering recreational opportunities and considerable social and commercial value (Spagnolo \& de Dear, 2003). The comfort that people experience in public spaces affects their use patterns and the acceptance of these places (Eliasson, Knez, Westerberg, Thorsson, \& Lindberg, 2007; Gehl, 1987; Givoni et al., 2003; Lenzholzer, 2012; Middel, Lukasczyk, \& Maciejewski, 2017; Thorsson, Lindqvist, \& Lindqvist, 2004; Tseliou, Tsiros, Lykoudis, \& Nikolopoulou, 2010; Walton, Dravitzki, \& Donn, 2007; Zacharias, Stathopoulos, \& Wu, 2001).

In the context of climate change, many biometeorology studies documented spatial variations in urban climate with a focus on thermal comfort (Hondula et al., 2017). Extensive research has been conducted to examine the essential determinants and construct a predictive modelling approach. However, in assessing outdoor comfort, existing indices and modelling approaches may not be directly applicable (Höppe, 2002; Nikolopoulou, Baker, \& Steemers, 2001; Nikolopoulou \&
Lykoudis, 2006). Therefore, it is crucial to fully understand the mechanisms underlying outdoor comfort assessments considering both place-related and person-related factors (See Fig. 1).

Looking back at the last decades, especially the last 10 years, the interest in this topic has increased significantly with a considerable boost in the number of publications (Rupp, Vásquez, \& Lamberts, 2015). With the development of knowledge on physics of heat exchange and physiology of thermoregulation, several indices have been proposed to evaluate thermal comfort based on the energetic balance assumption that refers to a steady and consistent environment settings (Johansson, Thorsson, Emmanuel, \& Krüger, 2014). The most widely applied thermal comfort index is perhaps the Predicted Mean Votes, which combined meteorological variables with subjects' metabolism rates and clothing levels, developed in climate chambers (Fanger, 1970). Some indices were formulated based on the concept that an equivalent temperature of an isothermal reference environment with certain indoor settings, where a reference person is maintained the same heat stress and thermoregulatory strain, equal to those under the actual assessing conditions, such as Physiological Equivalent Temperature (Höppe, 1999; Matzarakis, Mayer, \& Iziomon, 1999), Outdoor Standard Effective Temperature (Pickup \& De Dear, 2000) adapted

\footnotetext{
* Corresponding author.

E-mail addresses: y.peng@tue.nl (Y. Peng), t.feng@tue.nl (T. Feng), h.j.p.timmermans@tue.nl (H.J.P. Timmermans).

${ }^{1}$ ORCID: 0000-0002-5759-3164.

${ }^{2}$ ORCiD number: 0000-0002-8737-4632.
} 


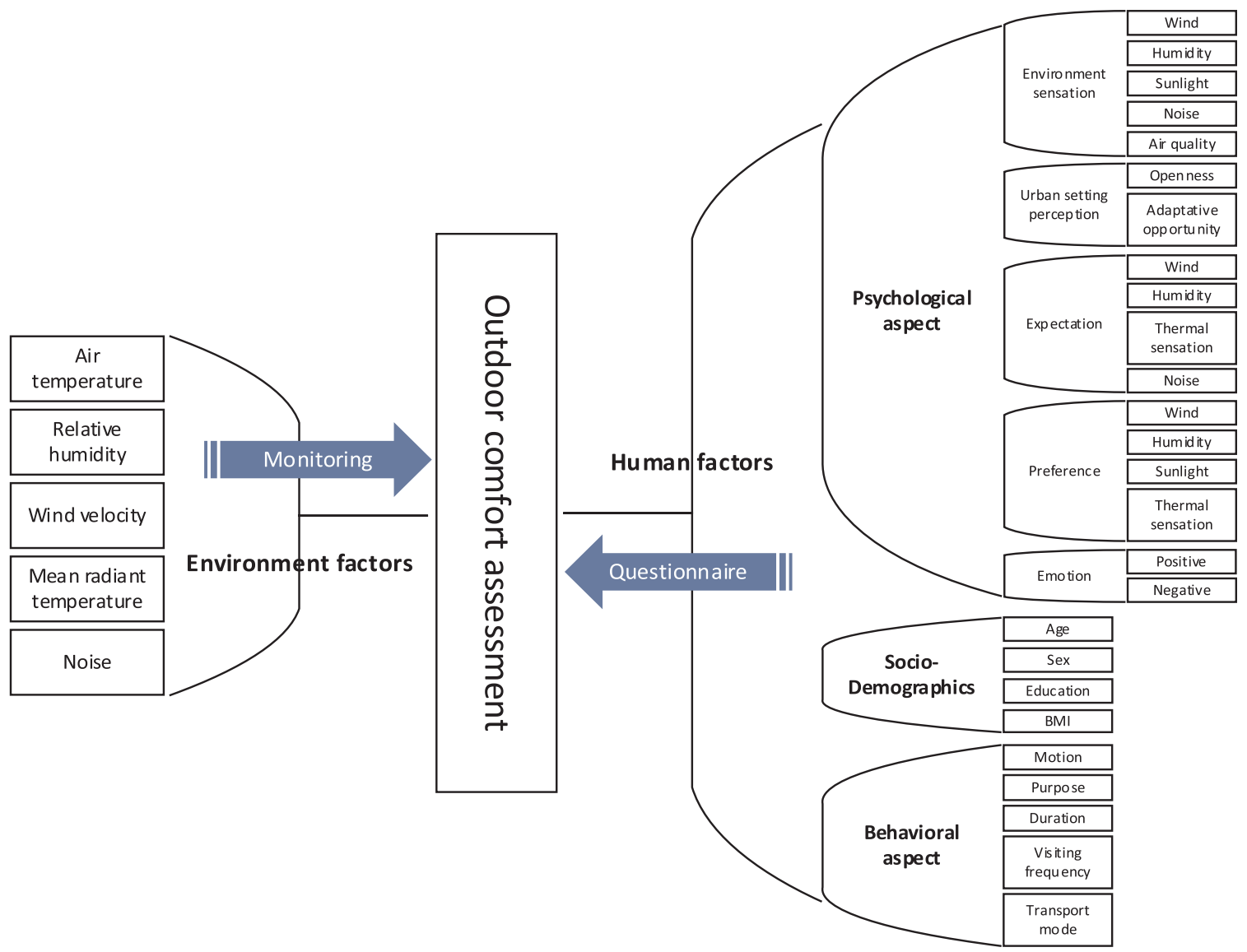

Fig. 1. Modeling framework of outdoor comfort assessment in urban public spaces.

from Standard Effective Temperature (Gagge, Fobelets, \& Berglund, 1986) and the newly developed Universal Thermal Comfort Index (Höppe, 2002; Jendritzky, de Dear, \& Havenith, 2012).

In this approach, individuals are assumed to be passive recipients of environment stimuli. The effects of given thermal conditions are mediated only by the physics of heat and mass exchanges between the body and the surrounding environment as well as physiological thermoregulation of human body. Comfort is supposed to emerge from the heat-balance. However, due to the dynamic and non-uniform microclimatic conditions in urban public spaces, the heat flow to and from the human body may not be balanced. Heat-balance theory lacks a coherent explanation to account for people's responses to outdoor conditions since it ignores the effects of psychological and behavioral factors (Lin \& Matzarakis, 2008; Stathopoulos, Wu, \& Zacharias, 2004). Evidenced by the results of numerous field studies, although the effects of microclimatic stresses can in part be predicted by physiological indices, still substantial difference remains between the actual comfort assessment and predicted assessment when applying the heat-balance index to naturally ventilated buildings (de Dear, Brager, \& Cooper, 1998; de Dear, 2004; Höppe, 2002; Humphreys \& Nicol, 1998; Humphreys \& Hancock, 2007; Kuras, Hondula, \& Brown-Saracino, 2015; Nicol \& Humphreys, 2010, 2002; van Hoof, 2010). There are even less reasons to assume this will not be the case in outdoor environments. Thus, the heat index and related indices have been criticized for the lack of universal applicability and the strict reliance on "ideal" conditions along with ignoring contextual attributes and human psychological and behavioral processes that influence comfort and the process of measuring outdoor comfort (See Fig. 2).

In addition, the equivalence of thermal comfort and neutral thermal sensation was challenged since the concept of "alliesthesia" was used to differentiate thermal pleasure from thermal neutrality (de Dear, 2011,
2009; Parkinson \& de Dear, 2015). The traditional methods which treat a neutral or acceptable condition as a substitute of a comfortable condition has also been criticized, since evidences were found that the temperature that people preferred was different from their neutral temperature (Cheung \& Jim, 2017). Thus, more broadly, the attainment of physiological thermal comfort may not be psychologically comfortable (Indraganti \& Rao, 2010). The cause-effect modelling approach simplifies the mechanism of comfort into a straightforward process flow from physical influences to physiological responses (Brager \& de Dear, 1998). The importance of other environmental stimuli (e.g. noise, air quality and sunlight/lighting, etc.) as well as psychological and behavioral factors in the assessment of (outdoor) comfort has generally been downplayed (Chappells \& Shove, 2005; Rossi, Anderini, Castellani, Nicolini, \& Morini, 2015; Vischer, 2008).

Comfort has been described as "the state of mind, which expresses satisfaction with the thermal environment" (ASHRAE, 2010). Conceptually, comfort is regarded as the result of a complex process influenced by norms and expectations, and it varies by seasons and cultures (Chappells \& Shove, 2005; Cole, Robinson, Brown, \& O'Shea, 2008; Nicol, Roaf, \& Nicol, 2017). Research found that individuals' mitigation or aggravation of discomfort depends on their personal background and local meteorological conditions, leading to an adaptive modelling approach (Humphreys \& Nicol, 1998). In line with this view, an implicit natural tendency of people to adapt to changing conditions is addressed. Both psychological adaptation and behavioral adjustment improved the tolerance of respondents to a significant wide range of thermal condition. Much progress has been made in terms of theory and practice with the introduction of the adaptive comfort model for indoor environments, which integrates people's thermal preferences and emphasized their behavioral reactions to avoid discomfort (de Dear et al., 1998; Humphreys \& Nicol, 1998; Lai \& Kontokosta, 2018; Manu, 


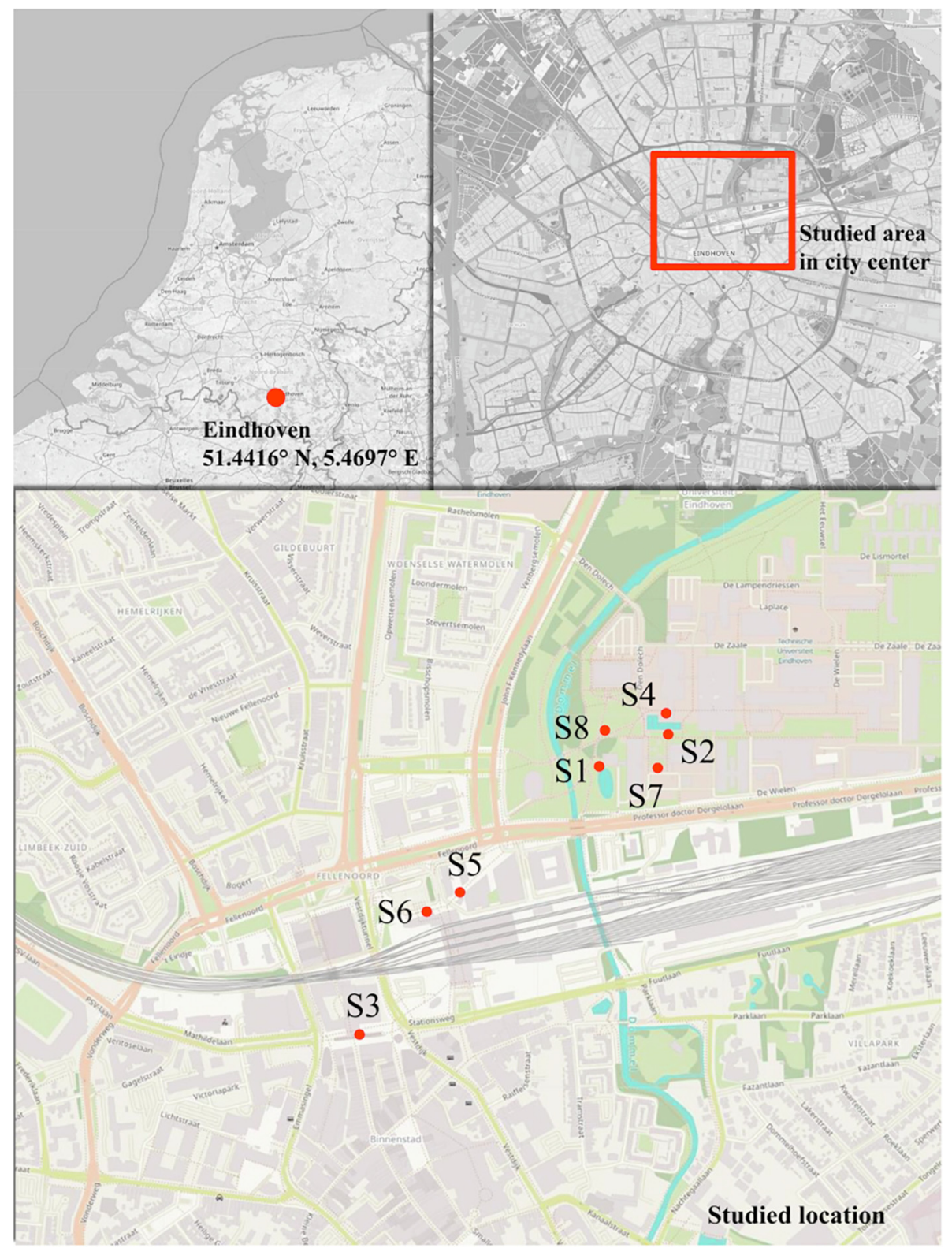

Fig. 2. Locations of field studies in Eindhoven.

Shukla, Rawal, Thomas, \& de Dear, 2016; Nicol \& Humphreys, 2002; Nicol et al., 2017; Singh, Mahapatra, \& Atreya, 2011; Singh, Ooka, Rijal, \& Takasu, 2017; Yao, Li, \& Liu, 2009).

It remains a challenge how to quantitatively describe individual's comfort because of the large influences given by the variability in microclimate, especially wind and solar conditions (Blocken \& Carmeliet, 2004; Coccolo, Kämpf, Scartezzini, \& Pearlmutter, 2016; Middel et al., 2017). On the other hand, empirical investigations related to the usage of urban spaces have revealed the limitations of static heat-balance theory and the dynamic adaptation of human beings to climatic and cultural differences (Aljawabra \& Nikolopoulou, 2010; Eliasson et al., 2007; Hwang \& Lin, 2007; Knez \& Thorsson, 2008; Knez, Thorsson, Eliasson, \& Lindberg, 2009; T. P. Lin, 2009; Middel, Selover, Hagen, \& Chhetri, 2016; Nikolopoulou et al., 2001; Nikolopoulou \& Lykoudis, 2006, 2007; Nikolopoulou \& Steemers, 2003; Spagnolo \& de Dear, 2003; Thorsson et al., 2004; Tseliou et al., 2010; Zacharias, Stathopoulos, \& Wu, 2004). The challenge arises when incorporating socio-demographic psychological perspectives that reflect and highlight inter-individual variations in the assessment of outdoor comfort
(Höppe, 2002). Substantial discrepancies have been discussed intensively in empirical outdoor studies. In line with the indoor adaptive model, people's adaptations in various manners in public spaces have been found to be correlated with the deviation of prediction by conventional indices (Hwang \& Lin, 2007; Knez \& Thorsson, 2006; Knez et al., 2009; Lenzholzer, 2010; Lenzholzer \& Koh, 2010; Lenzholzer \& van der Wulp, 2010; Middel et al., 2016; Moezzi, 2009; Nikolopoulou et al., 2001; Nikolopoulou \& Lykoudis, 2007; Thorsson et al., 2004).

In this paper, we argue that an extended framework is required to better understand and predict the assessment of outdoor comfort. In more details, the potential causal effects of psychological and behavioral factors has to be incorporated and taken into account comprehensively. According to the literatures, numerical analysis of the integrated impacts of diverse non-thermal behavior factors is still rare. No studies to date have systematically examined the influences with respect to individuals' socio-demographic characteristics, emotional status, expectations, preference and outdoor behavior (Langevin, Wen, \& Gurian, 2013). Further, linear effects have been challenged since the regular changes of some variables may lead to the variance in comfort 
assessment. This paper, therefore, aims to develop a theoretical framework to support a modelling approach of comfort assessment by taking into account a broader range of explanatory factors. Given the diversity of outdoor environments and the variability of individuals' psychological and socio-demographical characteristics, the opportunities and constraints of physical, social and behavioral contexts may affect comfort. On the other hand, microclimate in public spaces is characterized by a number of physical attributes (e.g. air temperature, relative humidity, wind speed, mean radiant temperature) which, in effect, are perceived by occupants individually with their own bias or propensity. In addition, we suppose that, before getting to a specific public space, an individual probably already formed a prospective microclimatic and environmental conditions based on his/her own knowledge, experience and information. This expected scenario was accordingly set as a cognitive reference within a local institutional acclimatization and experience (Lenzholzer, 2010; Lenzholzer \& Koh, 2010; Lenzholzer \& van der Wulp, 2010). Apparently, the physical spatial settings of public spaces offer both potential opportunities and constraints for individuals' adaptation. If people feel really discomfort in a certain outdoor open space, they will leave away immediately. Following the line of reasoning, people's visiting purposes, transportation modes and duration of outdoor exposure may affect their comfort assessment. Moreover, with an intention and forethought, people set goals and anticipate likely outcomes of prospective outdoor conditions and their actions. However, these were rarely investigated in existing studies.

The conceptual framework in this study was expanded to consider human comfort in a broader scope by incorporating physiological bodily sensation with a holistic perception in terms of person-related and place-related factors. The relative importance of diverse influences on comfort assessment was systematically examined. The simple causeeffect process in the conventional heat balance model was substituted by taking the mediating effects of human psychological and behavioral influences into account. Comfort used to be regarded as an independent and instantaneous process for modelling feasibility, however, in this study it was restored as the consecutive outcome from experiences and adaptations. When implementing outdoor activities, people normally have a special need and preference within a particular outdoor setting. Their comfort assessments are the outcome of the interaction between individual expectations and preferences and the opportunities and constraints induced by specific microclimatic and temporal-spatial settings within a particular socio-cultural context.

In summary, the real comfort assessment in outdoor environments represents a comprehensive judgment process in which individuals consider and realize their needs and preferences within a given urban temporal-spatial setting. The assessment of occupants in public space is based on their own experience and is related to specific purposes and corresponding outdoor behavior. In addition, their adaptation takes place with the specific outdoor activities in public spaces. Thus, we assume the underlying process of comfort assessment is determined by various impacts. Some person-related variables, like socio-demographics, emotional status, visiting purpose, transportation mode and experienced thermal condition characterize individual's own expectation and preference. These variables are dynamic and the values may continue updating when interacting with their surroundings. The adaptation which makes better comfort assessment is also involved from the interaction with environments. In this regard, comfort assessment is not treated as a static and independent process, but rather as the temporary outcome of a series of experience and consequent adaptation resulted from psychological and behavioral aspects.

\section{Methods}

A comprehensive conceptual consideration has been outlined, and the dataset was set up consequently through a systematic fieldwork and post-treatment. The fieldwork of this study centred with human outdoor comfort assessment should be designed in various urban public spaces with different features. Therefore, the principle of orthogonal fractional factorial design (FFD) was adopted for the selection of fieldwork locations. Further, during the structured survey, each respondent was invited to complete a questionnaire where relevant physical variables were automatically measured and recorded. The value of ambient microclimatic variables and noise, which was measured simultaneously in the survey, were averaged according to the corresponding start and end time of the interview. In order to acquire the underlying knowledge about comfort assessment in urban public spaces, the linear and non-linear modelling approaches were utilized based on an abovementioned expanded conceptual framework.

\subsection{Selection of studied location}

The city of Eindhoven is located in the south-east region of the Netherlands which has an oceanic climate, namely "Cfb" in KöppenGeiger classification as the typical climate of west coasts in higher middle latitudes of continents. The area has generally warm but not hot summers and mild winters, and a relatively narrow annual temperature range with few extreme temperatures.

In order to obtain unbiased estimates of the influence from settings of urban public spaces on individuals' outdoor comfort assessments, the related spatial and functional attributes should be independent and orthogonal with each other in studied locations. This precondition is typically violated in previous empirical investigations of outdoor comfort that rely on a random selection of locations (Johansson et al., 2014). Instead, this study applies the principle of orthogonal FFD to select the locations of the surveys and measurements. Considering the feasibility to find a suitable site location, a $1 / 4$ fraction of the Full Factorial Design, consisting of $32\left(=2^{5}\right)$ different profile combinations, was formed regarding to 5 essential spatial attributes. Based on the current literature, we identified the 5 attributes of urban settings which are critical to the assessment of comfort, including 1) W: landscape water or fountain, 2) R: facility for rest or smoking, 3) G: green lawn, 4) S: tree or shelter from sun and wind, and 5) A: catering and kiosk service. For each of these attributes, the two levels were specified and coded by " 1 " and " -1 ". A positive and negative value means a location has and has no corresponding features, respectively. In Table 1, we list 8 specific studied locations as S1 to S8. Each row in this table represents a location with a profile of the attribute levels. The locations are illustrated with a short description in Table 2.

\subsection{Field studies}

A series of systematic interviews and measurements were conducted in the selected locations of the city centre, Eindhoven, from 16th March to 10th April 2015. The fieldwork took place between 10:00 a.m. and 5:30 p.m. during 8 inconsecutive days without precipitation. In total, about 1000 participants joined the survey. However, some questionnaire forms with much missing data are invalid. We finally got 701 effective samples for further analysis.

Table 1

The orthogonal fractional factorial design.

\begin{tabular}{llllll}
\hline Specific spot & G & S & A & F & W \\
\hline S1 & 1 & 1 & 1 & 1 & 1 \\
S2 & 1 & -1 & -1 & -1 & 1 \\
S3 & -1 & 1 & -1 & 1 & 1 \\
S4 & -1 & -1 & 1 & -1 & 1 \\
S5 & -1 & -1 & -1 & 1 & -1 \\
S6 & -1 & 1 & 1 & -1 & -1 \\
S7 & 1 & -1 & 1 & 1 & -1 \\
S8 & 1 & 1 & -1 & -1 & -1 \\
\hline
\end{tabular}


Table 2

The selected sites for quasi-experiment.

\begin{tabular}{ll}
\hline Specific spot & \\
\hline S1 & A green space nearby "zwart doos" \\
S2 & A green space of StevenSimonplein \\
S3 & Central plaza in city center \\
S4 & Paved square of StevenSimonplein \\
S5 & A small paved square in Kennedyplein \\
S6 & Neckerspoel, northern square of central railway station \\
S7 & Small square between Verigo and Matrix \\
S8 & A green space nearby Auditorium
\end{tabular}

Table 3

Specification of sensors.

\begin{tabular}{llll}
\hline Variable & Sensor model & Resolution & Accuracy \\
\hline air temperature & NTC & $0.01 \mathrm{~K}$ & $\pm 0.05 \mathrm{~K}$ \\
relative humidity & CLIMA & $0.1 \%$ & $\pm 3 \%, 10-90 \%$ \\
wind velocity & CLIMA & $0.1 \mathrm{~m} / \mathrm{s}$ & $\pm 0.3 \mathrm{~m} / \mathrm{s} \mathrm{rms,}$ \\
& & $\mathrm{v} \leq 5 \mathrm{~m} / \mathrm{s}$ \\
& & $\pm 3 \% \mathrm{rms}$, \\
& & & $\begin{array}{c}\text { v } \\
\end{array}$ \\
& & & $\mathrm{v}>5 \mathrm{~m} / \mathrm{s}$ \\
globe temperature & NTC (inside a $150 \mathrm{~mm} / \mathrm{sm}$ \\
& black ball) & $0.01 \mathrm{~K}$ & $\pm 0.05 \mathrm{~K}$ \\
& & & \\
\hline
\end{tabular}

\subsubsection{Measurement}

Microclimate and acoustic condition were measured simultaneously with the survey. The assembled monitoring device was set up and tested well before the fieldwork. The monitoring sensors were equipped and connected with the data logger component powered by the mobile battery. The specification of sensors is listed in Table 3. According to ISO 7726 (Standard, 1998), the global temperature was measured using a NTC thermometer in a $150 \mathrm{~mm}$ diameter black ball, while air temperature and humidity were measured using a thermistor. Wind speed was measured using an ultrasonic anemometer. The well configured portable device located in the studied area is shown in Fig. 3. The sensors were mounted on a portable tripod at the standard height (Johansson et al., 2014), for the sake of outdoor use and easy to move.

The data logger automatically recorded the value of abovementioned physical variables with a one-second interval. In order to investigate the influence of radiation for human body including, solar short wave radiation and long wave radiation from the surrounding objects, mean radiant temperature $\left(T_{m r t}\right)$ was calculated according to ISO 7726 (Standard, 1998):

$T_{m r t}=\left[\left(T_{g}+273\right)^{4}+1.10 \times 10^{8} v^{0.6}\left(T_{g}-T_{a}\right) / \xi D^{0.4}\right]^{0.25}-273$

where $T_{g}$ is global temperature, $T_{a}$ is air temperature, $v$ is wind speed, $D$ is globe diameter $\left(=150 \mathrm{~mm}\right.$ ) of the black ball for measuring $T_{g}$, and $\xi$ is emissivity (0.95 in this research).

\subsubsection{Questionnaire and interview}

While studies in climate chambers have the advantage of testing under precisely controlled conditions, field studies are best used for assessing the potential impacts of behavioral or psychological aspects as they occur in realistic settings (de Dear et al., 1998). The most effective way to collect data on overall comfort assessment is to ask respondents directly, using questionnaires and/or interviews. The empirical data collected from field surveys can provide a wider perspective for outdoor comfort assessment.

The questionnaire form was prepared in both Dutch and English versions considering its feasibility for domestic and foreign participants. Based on the expanded conceptual framework, the entire questionnaire is composed of various sections. For each respondent, the collected information includes 1) socio-demographic characteristics

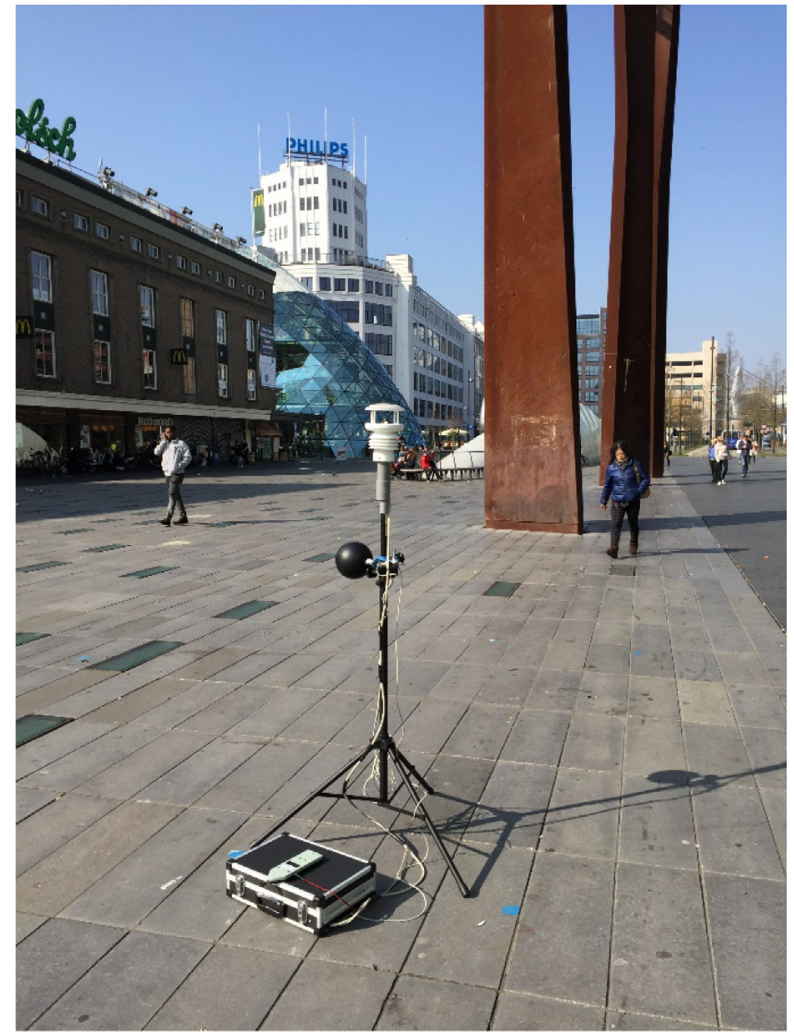

Fig. 3. The portable monitoring device in the field.

and emotional status, 2) expected thermal condition, expected humidity, expected wind speed and expected noise level, which are emerged before visiting and based on respondents' experience and knowledge about the studied outdoor space, 3) perceived humidity, perceived wind speed, perceived noise level, perceived sunlight condition and real-time overall comfort assessment, 4) preferred thermal condition, preferred humidity, preferred wind speed and preferred sunlight, and 5) related behavioral factors, including visiting frequency, outdoor activity duration, state of motion before interview, transportation mode and visiting purpose.

In the first section of the questionnaire, respondents were asked to fill in their detailed socio-demographic data (e.g. age, gender, height, weight, nationality, the health condition, education level, etc.). The clothing was not collected because a great diversity of materials and dressing codes could result in incorrect description and inaccuracy of insulation values. In particular, to examine the subjects' real-time emotion status, we used the Positive and Negative Affects Schedule (PANAS) proposed by Watson, Clark, and Tellegen (1988) in the questionnaire (see Table 4). Accordingly, respondents were invited to rate to what extent they experienced each of the twenty adjective words of emotions, on a 5-point Likert scale ranging from "not at all" to "extremely", to show how they feel at that moment. Half of the presented emotions concern positive effects and the other half negative effects. In the second section, the rating scales about stated sensation,

Table 4

Positive and Negative Affects Schedule (PANAS) in questionnaire form.

\begin{tabular}{|c|c|c|c|c|}
\hline $\begin{array}{l}1 \\
\text { very slightly or not at all }\end{array}$ & $\begin{array}{l}2 \\
\text { a little }\end{array}$ & $\begin{array}{l}3 \\
\text { moderately }\end{array}$ & $\begin{array}{l}4 \\
\text { quite a bit }\end{array}$ & $\begin{array}{l}5 \\
\text { extremely }\end{array}$ \\
\hline interested & guilty & irritable & & determined \\
\hline distressed & scared & alert & & attentive \\
\hline excited & hostile & ashamed & & jittery \\
\hline upset & enthusiastic & inspired & & active \\
\hline strong & proud & nervous & & afraid \\
\hline
\end{tabular}


perception, expectation and preference were designed following the ASHARE 7-point scale (Ashrae Standard, 2001). Different questions were formulated such as, what is your overall feeling of the present environment, and how comfortable do you perceive at present. In this way, respondents were asked to report their subjective sensations of various meteorological and environmental factors along with their assessment of the need satisfaction of outdoor activities and the overall comfort in the surveyed public spaces. This is due to that the thermal sensation and thermal comfort should be separated in non-uniform and dynamic conditions (Zhang \& Zhao, 2009).

Respondents were randomly invited to participate in the interview. Interviewers fully informed potential interviewees about the purpose of the survey and the expected time it would take. When the potential interviewee accepted, the exact start time were recorded. When the interview was finished, the interviewer wrote down the end time. The time and duration of the interview were used for synchronizing the survey data with the microclimate and noise measurements in order to calculate the precise average values of microclimatic variables and noise. All data were double-checked for a validation purpose. The structured interviews were administrated by research assistants. Each interview took about 10-15 min to complete. The on-site situation (see Fig. 4) shows how occupants used the space while the monitoring was conducted. The interviews were carried out not far away from the monitoring devices, mostly within $2 \mathrm{~m}$.

\subsection{Modelling}

Previous research has found a substantial discrepancy between the prediction results of thermal indices and respondents' actual comfort (Nikolopoulou et al., 2001; Nikolopoulou \& Lykoudis, 2006). This discrepancy could be attributed to the subjects' psychological and behavioral adaptation (de Dear et al., 1998; Humphreys \& Nicol, 1998; Nicol \& Humphreys, 2002; Nikolopoulou \& Steemers, 2003). In this paper, we expand the set of explanatory variables and also include respondents' emotional status, and their expectations, perceptions and preferences of microclimatic and environmental features. In addition, the influences of behavior related factors, like visiting frequency, visiting purpose, transportation mode and outdoor duration were also considered.
Because we assume that the marginal effect of at least some explanatory variables is not constant across their degree of intensity, we further estimate, in addition to the conventional linear regression model, a non-linear regression model through the Box-Cox transformation.

\subsubsection{Linear model with expanded factors}

We took both environment attributes and human factors into account in the multiple linear regression model. The explanatory variables were expanded compared with the previous models of thermal sensation or neutral temperature of adaptive models. With the multiple linear regression, a quantitative analysis have been conducted to reveal the effects of various aspects of outdoor environments and individual themselves. Hence,

$y=\beta_{0}+\sum_{i=1}^{n} \beta_{i} x_{i}+\varepsilon$

where $y$ is the value of overall comfort through the face-to-face interview, $\beta_{0}$ is the constant, $\beta_{i}$ is a parameter of the $i$ th factor, $x_{i}$ denotes the $i$ th variable which includes the physical features of a public space and respondents' information of socio-demographic, psychological and behavioral aspects.

\subsubsection{Non-linear model with Box-Cox transformation}

We attempt to explain and elaborate the effects of explanatory variables on the subjects' response of comfort assessment using a multiple linear regression model. However, this approach is limited in its linearity of the relationship between outdoor comfort and explanatory variables. To better understand the potential non-linear relationship between comfort assessment and predictors, the Box-Cox transformation (Box \& Tidwell, 1962) is employed on explanatory factors. As the estimation follows a stepwise procedure, only the variables with a reasonable $t$-value of coefficient $\beta$ and $\lambda$ could be transformed and remained. Ultimately, the non-linear regression model with the transformation was developed and estimated using the maximum likelihood method. The formulas of the regression model with Box-Cox transformation are presented below

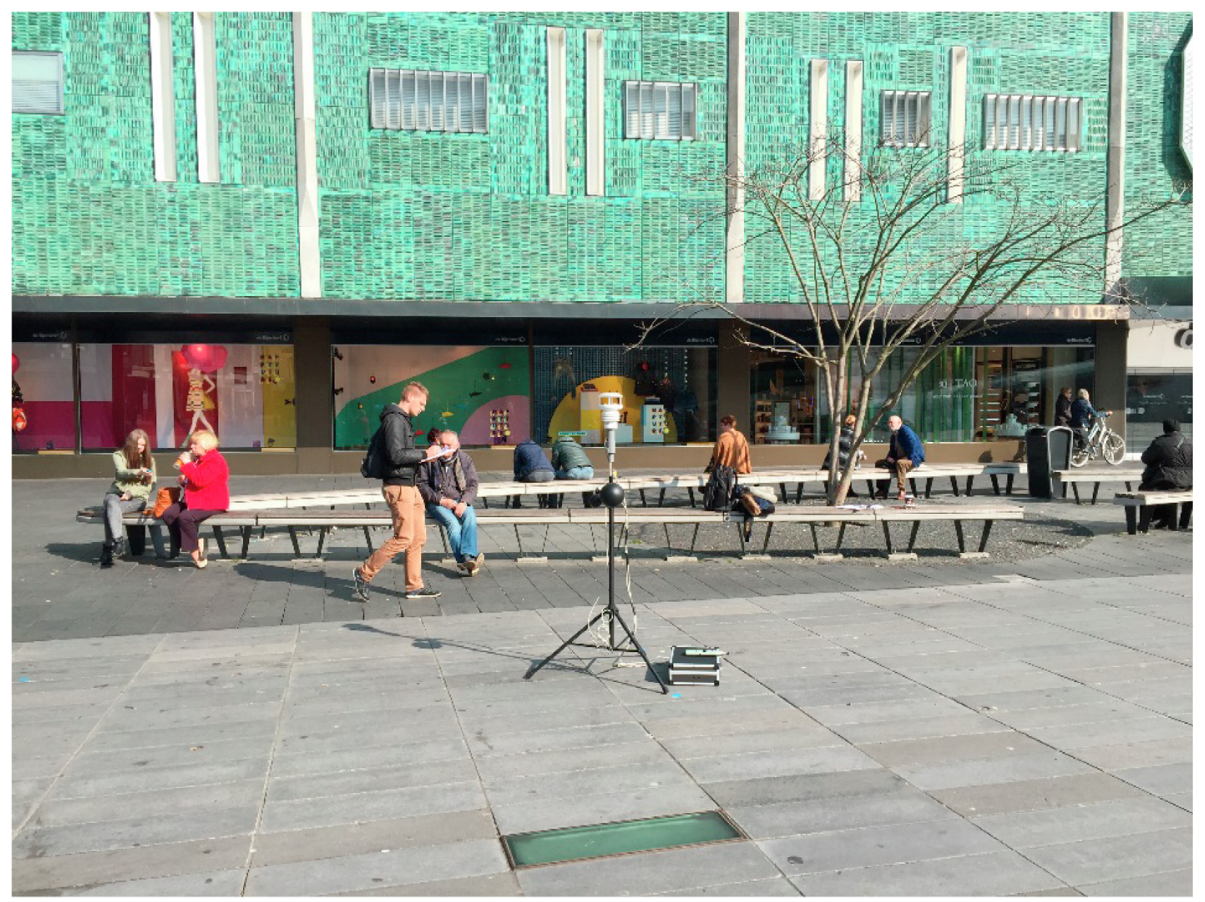

Fig. 4. Scene of the measurement and interview site. 
Table 5

Conditions of meteorological variables and noise level in the studied areas.

\begin{tabular}{|c|c|c|c|c|c|c|}
\hline Variable & Mean & Median & Minimum & Maximum & Discrepancy & SD \\
\hline Air temperature $\left({ }^{\circ} \mathrm{C}\right)$ & 11.0 & 9.7 & 4.2 & 24.7 & 20.5 & 4.6 \\
\hline Relative humidity (\%) & 56.3 & 55.5 & 24.9 & 91.2 & 66.3 & 17.6 \\
\hline Wind velocity $(\mathrm{m} / \mathrm{s})$ & 1.5 & 1.1 & 0.2 & 3.9 & 3.7 & 0.9 \\
\hline Mean radiant temperature $\left({ }^{\circ} \mathrm{C}\right)$ & 28.8 & 22.4 & 3.8 & 91.2 & 87.4 & 19.6 \\
\hline Noise $(\mathrm{db})$ & 64.9 & 65.7 & 51.04 & 72.82 & 21.78 & 4.3 \\
\hline
\end{tabular}

$y=\beta_{0}+\sum_{i=1}^{n} \beta_{i} x_{i}^{\prime}+\varepsilon^{\prime}$

$x_{i}^{\prime}= \begin{cases}\frac{x_{i}^{\lambda}-1}{\lambda}, & \mid \lambda \neq 0 \\ \ln x_{i}, & \mid \lambda=0\end{cases}$

where the dependent variable $y$ is comfort assessment, $\beta_{0}$ is the constant term, $\beta_{i}$ is a coefficient of the $i$ th explanatory factor, $x_{i}$ is the $i$ th BoxCox transformed independent variable, $\varepsilon^{\prime}$ is an error term and $\lambda$ is the coefficient of the Box-Cox transformation.

\section{Results and discussions}

\subsection{Descriptive statistics of meteorology and respondents}

The results of descriptive statistics are listed in Table 5-7. The environment condition of studied sites were characterized as microclimate with a significant variations, which are listed in Table 4. According to the sample distribution, seven out of ten respondents are Dutch people. In addition, the share of males is slightly higher than females. Over half of the respondents are aged between 16 and 35. The sample is varied in the sense that most of them have a normal stature with the magnitude of body mass index (BMI), ranging from 18.9 to 24.9. Moreover, respondents are varied by education level in the range between intermediate vocational college and master degree, only a fraction of them have a doctorate degree or an educational background of high school or below. In addition, the majority of respondents were well in terms of health condition, and the ones who reported being sick were just indisposition, such as cold, cough, etc.

The statistical results of respondents' behavior patterns in urban

Table 6

Descriptive statistics of social demographics.

\begin{tabular}{|c|c|c|}
\hline \multirow[t]{2}{*}{ Gender } & Male & $61.06 \%$ \\
\hline & Female & $38.94 \%$ \\
\hline \multirow[t]{7}{*}{ Age } & $<16$ & $2.28 \%$ \\
\hline & $16-25$ & $63.48 \%$ \\
\hline & $26-35$ & $14.55 \%$ \\
\hline & $36-45$ & $4.14 \%$ \\
\hline & $46-55$ & $3.85 \%$ \\
\hline & $56-65$ & $4.14 \%$ \\
\hline & $>65$ & $3.14 \%$ \\
\hline \multirow[t]{2}{*}{ Health condition } & Well & $91.87 \%$ \\
\hline & Sick & $8.13 \%$ \\
\hline \multirow[t]{4}{*}{ Body mass index } & $<18.5$ & $5.85 \%$ \\
\hline & $18.5-24.9$ & $71.18 \%$ \\
\hline & $25-29.9$ & $18.97 \%$ \\
\hline & $>30$ & $2.85 \%$ \\
\hline \multirow[t]{6}{*}{ Education level } & not higher than high school & $9.56 \%$ \\
\hline & intermediate vocation college & $18.26 \%$ \\
\hline & higher professional college & $13.69 \%$ \\
\hline & Bachelor & $30.67 \%$ \\
\hline & Master & $24.82 \%$ \\
\hline & Ph.D & $3.00 \%$ \\
\hline \multirow[t]{2}{*}{ Nationality } & Dutch & $77.18 \%$ \\
\hline & non-Dutch & $22.82 \%$ \\
\hline
\end{tabular}

Table 7

Descriptive statistics of behavioral factors.

\begin{tabular}{|c|c|c|}
\hline \multirow[t]{3}{*}{ Motion before interview } & sitting & $26.82 \%$ \\
\hline & standing & $15.83 \%$ \\
\hline & walking & $57.35 \%$ \\
\hline \multirow[t]{3}{*}{ Transport mode } & by foot & $37.66 \%$ \\
\hline & by bike & $22.26 \%$ \\
\hline & by bus, car and train & $40.08 \%$ \\
\hline \multirow[t]{5}{*}{ Frequency of visiting } & first time & $2.28 \%$ \\
\hline & scarcely & $13.69 \%$ \\
\hline & occasionally & $17.97 \%$ \\
\hline & sometimes & $26.11 \%$ \\
\hline & often & $39.95 \%$ \\
\hline \multirow[t]{5}{*}{ Total outdoor duration } & $<15 \min$ & $30.53 \%$ \\
\hline & $15-30 \mathrm{~min}$ & $30.53 \%$ \\
\hline & $30-60 \mathrm{~min}$ & $17.12 \%$ \\
\hline & $60-120 \mathrm{~min}$ & $10.70 \%$ \\
\hline & $>120 \mathrm{~min}$ & $11.12 \%$ \\
\hline \multirow[t]{4}{*}{ Duration in current area } & $<15 \min$ & $43.22 \%$ \\
\hline & $15-30 \mathrm{~min}$ & $30.81 \%$ \\
\hline & $30-60 \mathrm{~min}$ & $12.84 \%$ \\
\hline & $>60 \mathrm{~min}$ & $13.13 \%$ \\
\hline \multirow[t]{7}{*}{ Purpose of visiting } & transit & $20.97 \%$ \\
\hline & social activity & $6.56 \%$ \\
\hline & shopping & $16.83 \%$ \\
\hline & rest & $15.26 \%$ \\
\hline & leisure & $10.70 \%$ \\
\hline & passing by & $27.82 \%$ \\
\hline & other & $1.86 \%$ \\
\hline
\end{tabular}

public spaces are shown in Table 6. Before participating in the interview, around $43 \%$ respondents stayed in the public space. Most respondents spent less than one hour in outdoor environments before the interview and had been in the surveyed area shorter than $30 \mathrm{~min}$. In terms of visiting purpose, almost half respondents used it for commuting or transport, including passing by $(27.82 \%)$ and transit (20.97\%). Other respondents in the survey patronized the urban public space for specific needs. Respondents arrived in the surveyed area using different transportation modes, with a slightly larger proportion of walking and cycling, compared with driving or public transport. In addition, more than $66 \%$ of the respondents visited the surveyed place more than once per week, while less than $3 \%$ visited the place for the first time.

\subsection{Expanded human factor with linear modelling}

Results of the expanded linear regression and non-linear regression with Cox-Box transformation are included in Table 7. As the estimate of linear model illustrates, wind velocity and mean radiant temperature have a significant influence on comfort. In our survey, the average temperature measured in that season is $16^{\circ} \mathrm{C}$, which is far from the state of an uncomfortable hot temperature. The negative coefficient of wind velocity indicates that the faster the wind speed, the less comfort people feel in outdoor environments. In contrast, the mean radiant temperature has a positive impact on comfort. This is understandable because the mean radiant temperature affects the thermal loading, indicating that a higher heat loading may lead to more comfort in the context of 
Table 8

Estimation results of linear and non-linear regression models.

\begin{tabular}{|c|c|c|c|c|c|c|}
\hline \multirow[b]{2}{*}{$\mathrm{X}$} & \multicolumn{2}{|c|}{ Linear regression } & \multicolumn{4}{|c|}{ Non-linear regression with Box-Cox transformation } \\
\hline & $\beta$ & p-value & $\beta$ & $p$-value of $\beta$ & $\lambda$ & $p$-value of $\lambda$ \\
\hline (Constant) & $2.768^{* *}$ & 0.04 & $62.389^{* * * k}$ & 0.00 & 1 & $\mathrm{~N} / \mathrm{A}$ \\
\hline Air temperature & 0.012 & 0.78 & 0.028 & 0.30 & 1 & N/A \\
\hline Relative humidity & 0.001 & 0.90 & 0.003 & 0.37 & 1 & N/A \\
\hline Wind velocity & $-0.175^{*}$ & 0.07 & $-0.311^{* * * *}$ & 0.01 & $0.00^{*}$ & 0.06 \\
\hline Mean radiant temperature & $0.011 \mathrm{v}$ & 0.09 & $0.011^{*}$ & 0.06 & 1 & N/A \\
\hline Noise & -0.005 & 0.50 & $-0.327^{\text {*k*k: }}$ & 0.00 & $0.02^{\text {*k*k}}$ & 0.00 \\
\hline Age & -0.005 & 0.18 & $-41.468^{* * *}$ & 0.00 & $-1.49^{* \star * k}$ & 0.00 \\
\hline Gender ${ }^{a}$ & $0.301^{\text {****}}$ & 0.01 & $0.306^{\text {k***k}}$ & 0.01 & 1 & N/A \\
\hline Body mass index & 0.012 & 0.44 & $-45.174^{* * * k}$ & 0.00 & $-2.35^{* * * k}$ & 0.00 \\
\hline Education & $-0.136^{\text {***k }}$ & 0.00 & $-0.347^{\text {k*kk }}$ & 0.00 & $-0.27^{* * * k}$ & 0.00 \\
\hline Positive affects & $0.042^{\text {***k}}$ & 0.00 & $15.201^{\text {***k }}$ & 0.00 & $-0.76^{\text {***k}}$ & 0.00 \\
\hline Negative affects & $-0.039^{* * * *}$ & 0.00 & $-49.265^{* * *}$ & 0.00 & $-1.59^{* * *}$ & 0.00 \\
\hline Visiting frequency & $0.117^{\text {k***x }}$ & 0.01 & $0.119^{\text {kik }}$ & 0.02 & 1 & N/A \\
\hline Siting ${ }^{b}$ & 0.059 & 0.69 & 0.044 & 0.38 & 1 & $\mathrm{~N} / \mathrm{A}$ \\
\hline Standing ${ }^{b}$ & -0.034 & 0.85 & 0.077 & 0.36 & 1 & N/A \\
\hline Expected thermal sensation & $0.075^{* *}$ & 0.04 & $0.090^{*}$ & 0.07 & 0.69 & 0.24 \\
\hline Expected humidity & $0.093^{k * * k}$ & 0.01 & 0.088 & 0.01 & 1 & $\mathrm{~N} / \mathrm{A}$ \\
\hline Expected wind velocity & $-0.100^{\star * * *}$ & 0.01 & $-0.030^{* * k}$ & 0.00 & $1.85^{k+* * k}$ & 0.00 \\
\hline Expected noise & $0.072^{\text {** }}$ & 0.04 & $0.061^{k *}$ & 0.08 & 1 & $\mathrm{~N} / \mathrm{A}$ \\
\hline Perceived openness & $0.186^{\text {*k*k }}$ & 0.00 & $0.920^{k * * k}$ & 0.00 & $-0.14^{* \star * *}$ & 0.00 \\
\hline Perceived opportunities & 0.032 & 0.34 & 0.06 & 0.21 & 0.50 & 0.29 \\
\hline Total outdoor duration & $-0.102^{\text {***k}}$ & 0.01 & $-0.083^{* * * k}$ & 0.05 & 1 & $\mathrm{~N} / \mathrm{A}$ \\
\hline Perceived humidity & $-0.099^{* * * * *}$ & 0.01 & $-0.210^{\text {*k*k}}$ & 0.00 & $0.38^{\text {*** }}$ & 0.02 \\
\hline Perceived wind speed & $-0.125^{\text {**** }}$ & 0.00 & $-0.126^{\text {k.k.k}}$ & 0.00 & 1 & $\mathrm{~N} / \mathrm{A}$ \\
\hline Perceived sunlight & $0.152^{\text {***k }}$ & 0.00 & $0.590^{\text {k*k*k}}$ & 0.00 & $-0.29^{\text {***k}}$ & 0.00 \\
\hline Perceived noise & $-0.082^{* * *}$ & 0.03 & $-0.260^{* k *}$ & 0.02 & $0.14^{* * * *}$ & 0.00 \\
\hline Perceived air quality & $0.079^{* * *}$ & 0.03 & $0.240^{k * k}$ & 0.02 & $0.21^{\text {knkk }}$ & 0.01 \\
\hline Preferred thermal sensation & -0.044 & 0.26 & -0.032 & 0.28 & 1 & N/A \\
\hline Preferred humidity & 0.010 & 0.82 & 0.002 & 0.40 & 1 & N/A \\
\hline Preferred wind velocity & $0.093^{\text {****}}$ & 0.01 & $0.889^{* * * *}$ & 0.00 & $-0.91^{* \star * *}$ & 0.00 \\
\hline Preferred sunlight & $0.074^{* *}$ & 0.05 & $0.070^{*}$ & 0.07 & 1 & N/A \\
\hline By foot ${ }^{c}$ & $-0.303^{* * *}$ & 0.02 & $-0.318^{k * k}$ & 0.02 & 1 & N/A \\
\hline By bike ${ }^{c}$ & -0.089 & 0.53 & -0.144 & 0.24 & 1 & $\mathrm{~N} / \mathrm{A}$ \\
\hline Transit ${ }^{\mathrm{d}}$ & -0.068 & 0.86 & -0.272 & 0.31 & 1 & N/A \\
\hline Resting ${ }^{d}$ & 0.040 & 0.92 & -0.044 & 0.40 & 1 & $\mathrm{~N} / \mathrm{A}$ \\
\hline Social $^{\mathrm{d}}$ & -0.100 & 0.81 & -0.173 & 0.37 & 1 & $\mathrm{~N} / \mathrm{A}$ \\
\hline Shopping ${ }^{\mathrm{d}}$ & 0.246 & 0.53 & 0.185 & 0.36 & 1 & N/A \\
\hline Leisure $^{\mathrm{d}}$ & -0.062 & 0.88 & -0.142 & 0.38 & 1 & N/A \\
\hline \multirow[t]{2}{*}{ Passing by ${ }^{d}$} & -0.042 & 0.92 & -0.165 & 0.37 & 1 & $\mathrm{~N} / \mathrm{A}$ \\
\hline & \multicolumn{2}{|c|}{$R^{2}=0.371 /$ Adjusted $R^{2}=0.335$} & \multicolumn{4}{|c|}{$R^{2}=0.397 /$ Adjusted $R^{2}=0.361$} \\
\hline
\end{tabular}

${ }^{*}: p \leq 0.10^{* *}: p \leq 0.05^{* * *}: p \leq 0.01$.

local climate. In case of the air temperature and relative humidity, no significant effects were found. With respect to the acoustic environment, no linear relation was found between noise and the overall comfort assessment.

The socio-demographic characteristics (e.g. age, gender, body mass index and education) were utilized to represent respondents' physical status and knowledge background. According to the result of the linear regression model, no significant impacts of age and body mass index were found. However, gender significantly affects overall comfort assessment, whereas males express a higher degree of comfort. Likewise, the difference in thermal sensation between male and female under similar boundary conditions was explained in previous studies (Indraganti \& Rao, 2010; Karjalainen, 2012). In addition, the negative relation between education level and overall comfort means that people with higher education levels are inclined to express a lower degree of overall comfort.

Compared with the previous modeling approach, in this study, emotion and other psychological variables were quantitatively introduced and measured based on the expanded model. Results show that both positive affect and negative affect have significant and consistent impacts on comfort, respectively. In other words, a more positive emotion leads to a higher level of comfort assessment while a negative emotion results in a lower comfort assessment. From a psychological perspective, positive emotion may promote the potential adaptation by enhancing people's tolerance and enlarge the range of a perceived comfortable condition. More importantly, evidences show, when people have a higher expectation of prospective thermal sensation, humidity and noise level in an outdoor environment, they intend to feel more comfort. Additionally, if the people pre-estimated a higher outdoor wind speed, they tend to have lower comfort assessment. This maybe because the strong wind is always the irritating drawback and impressive in the context of local climate. Such an experience of being in the gusty wind may form the special cognitive effect to the users in open spaces, with regard to the expected consequence that windy circumstance leads to a negative evaluation of the comfort in real situations. However, results show the preferred wind speed has notable positive relation with comfort evaluation, which indicates that those who preferred higher wind speed environment felt more comfortable. In the meantime, the preferred sunlight is positively related to comfort evaluation. No apparent effects were found with respect to the preference of thermal sensation and humidity.

With respect to behavioral aspects, we considered the variables, such as visiting frequency for the studied public space, transportation modes (labeled with superscript $b$ and categorized as by foot, by bike considering by public transport and/or private car as the reference), purpose of being in surveyed outdoor space (labeled with superscript $c$ and categorized as transit, resting, social or cultural activity, shopping, leisure, passing by considering other as the reference), and total 
Table 9

Elasticity of significant explanatory variables.

\begin{tabular}{lll}
\hline Explanatory variables & Linear & Non-linear \\
\hline Wind velocity & -0.05 & -0.06 \\
Mean radiant temperature & 0.06 & N/A \\
Noise & $\mathrm{N} / \mathrm{A}$ & -0.07 \\
Age & $\mathrm{N} / \mathrm{A}$ & -0.06 \\
BMI & $\mathrm{N} / \mathrm{A}$ & -0.01 \\
Positive affects & 0.24 & 0.23 \\
Negative affects & -0.12 & -0.13 \\
Visiting frequency & 0.09 & $\mathrm{~N} / \mathrm{A}$ \\
Expected thermal sensation & 0.09 & 0.04 \\
Expected wind velocity & -0.03 & -0.09 \\
Expected humidity & 0.06 & $\mathrm{~N} / \mathrm{A}$ \\
Expected noise & 0.07 & $\mathrm{~N} / \mathrm{A}$ \\
Total outdoor duration & -0.05 & $\mathrm{~N} / \mathrm{A}$ \\
Preferred wind velocity & 0.07 & $\mathrm{~N} / \mathrm{A}$ \\
Preferred sunlight & 0.06 & $\mathrm{~N} / \mathrm{A}$ \\
Perceived openness & 0.20 & 0.14 \\
Perceived wind velocity & -0.11 & $\mathrm{~N} / \mathrm{A}$ \\
Perceived humidity & -0.06 & -0.06 \\
Perceived sunlight & 0.11 & 0.08 \\
Perceived noise & -0.07 & -0.06 \\
Perceived air quality & 0.08 & 0.07 \\
\hline
\end{tabular}

duration of outdoor activity. As shown in the results, many behavioral variables are statistically significant. The positive estimate of visiting frequency indicates that the more frequent a respondent visits the studied area the higher their perceived comfort. This is understandable considering the fact that comfort perception could depend on how well people know the place in the sense that positive comfort evaluation may be raised by users who visited the public space more often. In addition, respondents who either stay longer in outdoor environments or come by foot intend to degrade their comfort assessment. It means a longer duration of outdoor stay or walking a lot has a negative effect on comfort, i.e. fatigue, boring, etc. However, such a partial effect may not be fully explained in the way as it is estimated, because it may interact with other contextual variables, i.e. travel purpose and transportation mode.

Furthermore, the effects of the perceived spatial attributes are also revealed. The representative variables are subjective evaluation of opportunities provided by urban facilities and perceived openness of the public space. It is found the perceived openness has a significant influence on comfort whereas a positive correlation exists between acceptable openness and comfort assessment. If the building blocks enclose a public space to an unacceptable extent, it may cause a negative effect on users' comfort.

Overall, the explanatory variables interpret the comfort with an acceptable goodness-of-fit (adjusted $\mathrm{R}^{2}=0.335$ ). We consider that the $R^{2}$ value is not directly comparable with other typical studies in which the model did not systematically focus on individuals' actual evaluation of comfort. In addition, we involved psychological and behavioral factors which means some instrumental error is unavoidable. More importantly, results of the expanded linear model show that most psychological behavior variables have a significant impact on outdoor comfort. This confirms our original assumption and the expanded conceptual framework.

\subsection{Nonlinear relationship with Box-Cox transformation}

As presented in Table 8, the significance of most explanatory variables in the nonlinear model is improved relative to the linear model. The remarkable boosting of $\mathrm{t}$-value of $\beta$ took place on wind velocity and noise related to the physical attributes of public spaces, as well as age and body mass index which are related to the respondents. $\mathrm{A} \lambda$ which is not equal to 1 means the related explanatory variable takes a specific transformation. For example, the transformation of wind speed approximates to the logarithm $(\lambda=0)$, while that for the mean radiant temperature is close to a power function $(\lambda=-2.08)$. It is remarkable that the approximate logarithmic effect of noise level on comfort evaluation was extracted by the Box-Cox transformation. In addition, both age and body mass index show their significant negative effects on comfort, which indicates that the elderly and people with higher body mass index feel less comfortable. However, in the linear regression model, the body mass index had little impact on comfort evaluation. Nevertheless, the conclusion regarding the negative effects of body mass index is in line with the results found in previous studies that also found the increase of body mass index can reduce the value of thermal sensation to some extent (Tuomaala, Holopainen, Piira, \& Airaksinen, 2013).

Similarly, the estimates of variables without a transformation in the non-linear model almost remain the same as in linear model. Taking the meteorological variables as an example, the impacts of air temperature and humidity on comfort in the non-linear model is not different from that in the linear regression model. Similar results can be found that male is inclined to give more comfortable evaluation. In addition, respondents' visiting frequency and their expectation of humidity and perception of wind have a similar impact on comfort assessment as that in the linear regression model. The duration of outdoor staying and walking still negatively affect the overall comfort assessment.

The result of non-linear regression model with Box-Cox transformation yields a slightly better goodness-of-fit (adjusted $R^{2}=0.361$ ) than the linear model. This means the actual outdoor comfort assessment, as a result of respondents' mental activities and judgements, may be better linked to the variables of the environment and individuals, in a nonlinear way.

To further explore the variables' contribution to predict outdoor comfort assessment in urban public spaces, an elasticity analysis was conducted, as shown in Table 9. We found that some human factors have relatively a larger elasticity, such as the emotional status, perception on openness of public space, sensation of wind velocity and sunlight exposure exert. This means the change of values of these variables will have a larger effect on comfort assessment than other variables.

\section{Conclusion}

In this study, an expanded conceptual framework of comfort assessment in urban public spaces was proposed by incorporating the physical environment attributes and people's psychological and behavioral factors. The selection of the fieldwork location based on an orthogonal experiment design avoids the possible effects of the partial observations which were always neglected in previous studies. The nonlinear analysis further uncovered and explained the effects that are hindered in linear models. Theoretically, the methodology proposed in this paper can be applied also in various climate zones and diverse cultural contexts.

The model results provide a convincing evidence that the mechanism of comfort assessment is beyond a single energy exchange dimension. A linear relationship between comfort and an expanded set of factors was found, and later improved by a non-linear model using a Box-Cox transformation. To the best of our knowledge, this is the first work to develop such a numerical comprehensive model with extended determinants in outdoor comfort research. The findings provide more insights on the actual assessment of outdoor comfort. The social-economical characteristics significantly affect comfort assessment, so does the emotional status. Other than the variations between different individuals, the psychological and behavioral factors were also found to play an important role in comfort assessment.

In this regard, we elaborate a new way to understand outdoor comfort based on the interactions between the variables related to users and outdoor spaces. The findings bring a lot of implications for research and practices, especially for urban infrastructure design and planning. 
Designer may become aware of the complexity of comfort assessment mechanism instead of only considering the thermal condition. The importance of the subjective psychological factors may prompt the designer to pay more attention on satisfying the various requirements of potential occupants. The necessary modifications to create diverse conditions of wind and sunlight in the context of local climate and culture still improve the attractiveness of public spaces. Thus, the design of public spaces should respect the needs of occupants with different socio-demographic backgrounds. Further, more attention should be drawn to the settings and facilities, such as tree, shelter, seats, as these can provide opportunities for occupants' adaptations.

This study addressed the issues related to actual outdoor comfort assessment. To reduce the potential error in the measurement of microclimate data, we set up the monitoring device at least $20 \mathrm{~min}$ before the field study. This is mainly due to the spherical globe thermometer needs some time to get stable. However, this cannot rule out the error completely in the measurement, e.g. under a strong wind condition. Thus, future research is needed to measure the microclimate data using the devices with a higher accuracy. This may also improve the overall explanatory of the model. In addition, the extended framework provides a more sophisticated reference for the research and practice related to outdoor comfort assessment. In spite that the approach is generalizable, the data used for model estimation was collected in the city of the Netherlands, which means the variations of the physical measurements may not be as large as expected from a glable view. Thus, the findings may not fully reflect the effects of every climate context, e.g. tropical areas, arid areas, and cultural context, e.g. Nordic, East Asia. Therefore, future research is needed to apply or extend the proposed model in a wider spectrum of areas.

\section{Appendix A. Supplementary data}

Supplementary data to this article can be found online at https:// doi.org/10.1016/j.landurbplan.2019.103594.

\section{References}

Aljawabra, F., \& Nikolopoulou, M. (2010). Influence of hot arid climate on the use of outdoor urban spaces and thermal comfort: Do cultural and social backgrounds matter? Intelligent Buildings International, 2(3), 198-207. https://doi.org/10.3763/ inbi.2010.0046.

ASHRAE (2010). ANSI/ASHRAE Standard 55-2010. ASHRAE Inc. https://doi.org/ISSN 1041-2336.

Ashrae Standard (2001). ASHRAE Handbook 2001 Fundamentals, Vol. 53Ashrae Standard https://doi.org/10.1017/CBO9781107415324.004.

Blocken, B., \& Carmeliet, J. (2004). Pedestrian wind environment around buildings: Literature review and practical examples. Journal of Thermal Envelope and Building Science, 28(2), 107-159. https://doi.org/10.1177/1097196304044396.

Box, G. E. P., \& Tidwell, P. W. (1962). Transformation of the Independent Variables. Technometrics, 4(4), 531-550. http://www.jstor.org/stable/1266288.

Brager, G. S., \& de Dear, R. J. (1998). Thermal adaptation in the built environment: A literature review. Energy and Buildings, 27(1), 83-96. https://doi.org/10.1016/ S0378-7788(97)00053-4.

Chappells, H., \& Shove, E. (2005). Debating the future of comfort: Environmental sustainability, energy consumption and the indoor environment. Building Research and Information, 33(1), 32-40. https://doi.org/10.1080/0961321042000322762.

Cheung, P. K., \& Jim, C. Y. (2017). Determination and application of outdoor thermal benchmarks. Building and Environment, 123, 333-350. https://doi.org/10.1016/j. buildenv. 2017.07.008.

Coccolo, S., Kämpf, J., Scartezzini, J. L., \& Pearlmutter, D. (2016). Outdoor human comfort and thermal stress: A comprehensive review on models and standards. Urban Climate, 18, 33-57. https://doi.org/10.1016/j.uclim.2016.08.004.

Cole, R. J., Robinson, J., Brown, Z., \& O'Shea, M. (2008). Re-contextualizing the notion of comfort. Building Research and Information, 36(4), 323-336. https://doi.org/10.1080/ 09613210802076328

de Dear, R. (2004). Thermal comfort in practice. Indoor Air, Supplement, 14(SUPPL. 7), 32-39. https://doi.org/10.1111/j.1600-0668.2004.00270.x.

de Dear, R. (2009). The theory of thermal comfort in naturally ventilated indoor environments - "The Pleasure Principle". International Journal of Ventilation, 8(3), 243-250. https://doi.org/10.1080/14733315.2009.11683849.

de Dear, R. (2011). Revisiting an old hypothesis of human thermal perception: Alliesthesia. Building Research \& Information, 39(2), 108-117. https://doi.org/10 1080/09613218.2011.552269.

de Dear, R., Brager, G., \& Cooper, D. (1998). Developing an adaptive model of thermal comfort and preference. ASHRAE Transactions, 104(Part 1), 1-18.

Eliasson, I., Knez, I., Westerberg, U., Thorsson, S., \& Lindberg, F. (2007). Climate and behaviour in a Nordic city. Landscape and Urban Planning, 82(1-2), 72-84. https:// doi.org/10.1016/j.landurbplan.2007.01.020.

Fanger, P. O. (1970). Thermal comfort. Analysis and applications in environmental engineering.

Gagge, A. P., Fobelets, A. P., \& Berglund, L. G. (1986). A standard predictive index of human response to the thermal environment. ASHRAE Transactions, 1, 709-731.

Gehl, J. (1987). Life between buildings: Using public space. The City Reader.

Givoni, B., Noguchi, M., Saaroni, H., Pochter, O., Yaakov, Y., Feller, N., \& Becker, S (2003). Outdoor comfort research issues. Energy and Buildings, 35(1), 77-86. https:// doi.org/10.1016/S0378-7788(02)00082-8.

Hondula, D. M., Balling, R. C., Andrade, R., Scott Krayenhoff, E., Middel, A., Urban, A., .. Sailor, D. J. (2017). Biometeorology for cities. International Journal of Biometeorology, 61, 59-69. https://doi.org/10.1007/s00484-017-1412-3.

Höppe, P. (1999). The physiological equivalent temperature - a universal index for the biometeorological assessment of the thermal environment. International Journal of Biometeorology, 43(2), 71-75. https://doi.org/10.1007/s004840050118.

Höppe, P. (2002). Different aspects of assessing indoor and outdoor thermal comfort. Energy and Buildings, 34(6), 661-665. https://doi.org/10.1016/S0378-7788(02) 00017-8.

Humphreys, M. A., \& Nicol, J. F. (1998). Understanding the adaptive approach.pdf.

Humphreys, M. A., \& Hancock, M. (2007). Do people like to feel "neutral"? Exploring the variation of the desired thermal sensation on the ASHRAE scale. Energy and Buildings, 39(7), 867-874. https://doi.org/10.1016/j.enbuild.2007.02.014.

Hwang, R.-L., \& Lin, T.-P. (2007). Thermal comfort requirements for occupants of semioutdoor and outdoor environments in hot-humid regions. Architectural Science Review, 50(4), 357-364. https://doi.org/10.3763/asre.2007.5043.

Indraganti, M., \& Rao, K. D. (2010). Effect of age, gender, economic group and tenure on thermal comfort: A field study in residential buildings in hot and dry climate with seasonal variations. Energy and Buildings, 42(3), 273-281. https://doi.org/10.1016/j. enbuild.2009.09.003.

Jendritzky, G., de Dear, R., \& Havenith, G. (2012). UTCI — Why another thermal index ? International Journal of Biometeorology, 421-428. https://doi.org/10.1007/s00484011-0513-7.

Johansson, E., Thorsson, S., Emmanuel, R., \& Krüger, E. (2014). Instruments and methods in outdoor thermal comfort studies - The need for standardization. Urban Climate, 10(P2), 346-366. https://doi.org/10.1016/j.uclim.2013.12.002.

Karjalainen, S. (2012). Thermal comfort and gender: A literature review. Indoor Air, 22(2), 96-109. https://doi.org/10.1111/j.1600-0668.2011.00747.x.

Knez, I., \& Thorsson, S. (2006). Influences of culture and environmental attitude on thermal, emotional and perceptual evaluations of a public square. International Journal of Biometeorology, 50(5), 258-268. https://doi.org/10.1007/s00484-006 0024-0.

Knez, I., \& Thorsson, S. (2008). Thermal, emotional and perceptual evaluations of a park: Cross-cultural and environmental attitude comparisons. Building and Environment, 43(9), 1483-1490. https://doi.org/10.1016/j.buildenv.2007.08.002.

Knez, I., Thorsson, S., Eliasson, I., \& Lindberg, F. (2009). Psychological mechanisms in outdoor place and weather assessment: Towards a conceptual model. International Journal of Biometeorology, 53(1), 101-111. https://doi.org/10.1007/s00484-008 0194-z.

Kuras, E. R., Hondula, D. M., \& Brown-Saracino, J. (2015). Heterogeneity in individually experienced temperatures (IETs) within an urban neighborhood: Insights from a new approach to measuring heat exposure. International Journal of Biometeorology, 59(10), 1363-1372. https://doi.org/10.1007/s00484-014-0946-x.

Lai, Y., \& Kontokosta, C. E. (2018). Quantifying place: Analyzing the drivers of pedestrian activity in dense urban environments. Landscape and Urban Planning, 180(July 2017), 166-178. https://doi.org/10.1016/j.landurbplan.2018.08.018.

Langevin, J., Wen, J., \& Gurian, P. L. (2013). Modeling thermal comfort holistically: Bayesian estimation of thermal sensation, acceptability, and preference distributions for office building occupants. Building and Environment, 69, 206-226. https://doi.org/ 10.1016/j.buildenv.2013.07.017.

Lenzholzer, S. (2010). Engrained experience-a comparison of microclimate perception schemata and microclimate measurements in Dutch urban squares. International Journal of Biometeorology, 54(2), 141-150. https://doi.org/10.1007/s00484-0090262-z.

Lenzholzer, S. (2012). Research and design for thermal comfort in Dutch urban squares. Resources, Conservation and Recycling, 64, 39-48. https://doi.org/10.1016/j. resconrec.2011.06.015

Lenzholzer, S., \& Koh, J. (2010). Immersed in microclimatic space: Microclimate experience and perception of spatial configurations in Dutch squares. Landscape and Urban Planning, 95(1-2), 1-15. https://doi.org/10.1016/j.landurbplan.2009.10.013.

Lenzholzer, S., \& van der Wulp, N. Y. (2010). Thermal experience and perception of the built environment in Dutch urban squares. Journal of Urban Design, 15(3), 375-401. https://doi.org/10.1080/13574809.2010.488030.

Lin, T. P. (2009). Thermal perception, adaptation and attendance in a public square in hot and humid regions. Building and Environment, 44(10), 2017-2026. https://doi.org/10. 1016/j.buildenv.2009.02.004.

Lin, T.-P., \& Matzarakis, A. (2008). Tourism climate and thermal comfort in Sun Moon Lake, Taiwan. International Journal of Biometeorology, 52(4), 281-290. https://doi. org/10.1007/s00484-007-0122-7.

Manu, S., Shukla, Y., Rawal, R., Thomas, L. E., \& de Dear, R. (2016). Field studies of thermal comfort across multiple climate zones for the subcontinent: India model for adaptive comfort (IMAC). Building and Environment, 106, 422-426. https://doi.org/ 10.1016/j.buildenv.2016.07.015.

Matzarakis, A., Mayer, H., \& Iziomon, M. G. (1999). Applications of a universal thermal 
index: Physiological equivalent temperature. International Journal of Biometeorology, 43(2), 76-84. https://doi.org/10.1007/s004840050119.

Middel, A., Lukasczyk, J., \& Maciejewski, R. (2017). Sky view factors from synthetic fisheye photos for thermal comfort routing-A case study in phoenix, Arizona. Urban Planning, 2(1), 19. https://doi.org/10.17645/up.v2i1.855.

Middel, A., Selover, N., Hagen, B., \& Chhetri, N. (2016). Impact of shade on outdoor thermal comfort-a seasonal field study in Tempe, Arizona. International Journal of Biometeorology, 60(12), 1849-1861. https://doi.org/10.1007/s00484-016-1172-5.

Moezzi, M. (2009). Are comfort expectations of building occupants too high? Building Research and Information, 37(1), 79-83. https://doi.org/10.1080/ 09613210802611009.

Nicol, J. F., \& Humphreys, M. A. (2002). Adaptive thermal comfort and sustainable thermal standards for buildings. Energy and Buildings, 34, 563-572. https://doi.org/ 10.1016/S0378-7788(02)00006-3.

Nicol, F., \& Humphreys, M. (2010). Derivation of the adaptive equations for thermal comfort in free-running buildings in European standard EN15251. Building and Environment, 45(1), 11-17. https://doi.org/10.1016/j.buildenv.2008.12.013.

Nicol, J. F., Roaf, S., \& Nicol, J. F. (2017). Rethinking thermal comfort. Building Research \& Information, 3218(November), https://doi.org/10.1080/09613218.2017.1301698.

Nikolopoulou, M., Baker, N., \& Steemers, K. (2001). Thermal comfort in outdoor urban spaces: Understanding the Human parameter. Solar Energy, 70(3), 227-235. https:// doi.org/10.1016/S0038-092X(00)00093-1.

Nikolopoulou, M., \& Lykoudis, S. (2006). Thermal comfort in outdoor urban spaces: Analysis across different European countries. Building and Environment, 41(11), 1455-1470. https://doi.org/10.1016/j.buildenv.2005.05.031.

Nikolopoulou, M., \& Lykoudis, S. (2007). Use of outdoor spaces and microclimate in a Mediterranean urban area. Building and Environment, 42(10), 3691-3707. https://doi. org/10.1016/j.buildenv.2006.09.008.

Nikolopoulou, M., \& Steemers, K. (2003). Thermal comfort and psychological adaptation as a guide for designing urban spaces. Energy and Building, 35(1), 95-101.

Parkinson, T., \& de Dear, R. (2015). Thermal pleasure in built environments: Physiology of alliesthesia. Building Research \& Information, 43(3), 288-301. https://doi.org/10. 1080/09613218.2015.989662.

Pickup, J., \& De Dear, R. (2000). An outdoor thermal comfort index (OUT_SET*)-part Ithe model and its assumptions. In In Biometeorology and urban climatology at the turn of the millenium. Selected Papers from the Conference ICB-ICUC (p. Vol. 99, pp. 279-283). Available from: https://www.researchgate.net/profile/Richard De Dear/ publication/268983313 An outdoor thermal comfort index OUT-SET_-_Part I - The model_and_its_assumptions/links/567a4b6308ae40c0e27e9397.pdf.

Rossi, F., Anderini, E., Castellani, B., Nicolini, A., \& Morini, E. (2015). Integrated improvement of occupants' comfort in urban areas during outdoor events. Building and Environment, 93(P2), 285-292. https://doi.org/10.1016/j.buildenv.2015.07.018.

Rupp, R. F., Vásquez, N. G., \& Lamberts, R. (2015). A review of human thermal comfort in the built environment. Energy and Buildings, 105, 178-205. https://doi.org/10.1016/ j.enbuild.2015.07.047.

Singh, M. K., Mahapatra, S., \& Atreya, S. K. (2011). Adaptive thermal comfort model for different climatic zones of North-East India. Applied Energy, 88(7), 2420-2428. https://doi.org/10.1016/j.apenergy.2011.01.019.
Singh, M. K., Ooka, R., Rijal, H. B., \& Takasu, M. (2017). Adaptive thermal comfort in the offices of North-East India in autumn season. Building and Environment, 124, 14-30. https://doi.org/10.1016/j.buildenv.2017.07.037.

Spagnolo, J., \& de Dear, R. (2003). A field study of thermal comfort in outdoor and semioutdoor environments in subtropical Sydney Australia. Building and Environment, 38(5), 721-738. https://doi.org/10.1016/S0360-1323(02)00209-3.

Standard, I. (1998). ISO 7726 Ergonomics of the thermal environment - Instruments for measuring physical quantities. ISO Standard, 1998, 1-56 https://doi.org/ISO 7726:1998 (E).

Stathopoulos, T., Wu, H., \& Zacharias, J. (2004). Outdoor human comfort in an urban climate. Building and Environment, 39(3), 297-305. https://doi.org/10.1016/j. buildenv.2003.09.001.

Thorsson, S., Lindqvist, M., \& Lindqvist, S. (2004). Thermal bioclimatic conditions and patterns of behaviour in an urban park in Göteborg, Sweden. International Journal of Biometeorology. https://doi.org/10.1007/s00484-003-0189-8.

Tseliou, A., Tsiros, I. X., Lykoudis, S., \& Nikolopoulou, M. (2010). An evaluation of three biometeorological indices for human thermal comfort in urban outdoor areas under real climatic conditions. Building and Environment, 45(5), 1346-1352. https://doi. org/10.1016/j.buildenv.2009.11.009.

Tuomaala, P., Holopainen, R., Piira, K., \& Airaksinen, M. (2013). Impact of individual characteristics - Such as age, gender, BMI, and fitness - on human thermal sensation. In Proceedings of BS 2013: 13th Conference of the International Building Performance Simulation Association (pp. 2305-2311). Available from: https://www. scopus.com/inward/record.uri?eid =2-s2.0-84886692050\&partnerID = 40\&md5 = 7932ee00a0fda74d75bbac080d8f12b3.

van Hoof, J. (2010). Thermal comfort: Research and practice. Frontiers in Bioscience, 15(1), 765. https://doi.org/10.2741/3645.

Vischer, J. C. (2008). Towards a user-centred theory of the built environment. Building Research \& Information, 36(3), 231-240. https://doi.org/10.1080/ 09613210801936472.

Walton, D., Dravitzki, V., \& Donn, M. (2007). The relative influence of wind, sunlight and temperature on user comfort in urban outdoor spaces. Building and Environment, 42(9), 3166-3175. https://doi.org/10.1016/j.buildenv.2006.08.004.

Watson, D., Clark, L. A., \& Tellegen, A. (1988). Development and validation of brief measures of positive and negative affect: The PANAS scales. Journal of Personality and Social Psychology, 54(6), 1063-1070. https://doi.org/10.1037/0022-3514.54.6.1063.

Yao, R., Li, B., \& Liu, J. (2009). A theoretical adaptive model of thermal comfort Adaptive Predicted Mean Vote (aPMV). Building and Environment, 44(10), 2089-2096. https://doi.org/10.1016/j.buildenv.2009.02.014.

Zacharias, J., Stathopoulos, T., \& Wu, H. (2001). Microclimate and downtown open space activity. Environment and Behavior, 33(2), 296-315. https://doi.org/10.1177/ 0013916501332008 .

Zacharias, J., Stathopoulos, T., \& Wu, H. (2004). Spatial behavior in San Francisco's Plazas. Environment and Behavior, 36(5), 638-658. https://doi.org/10.1177/ 0013916503262545.

Zhang, Y., \& Zhao, R. (2009). Relationship between thermal sensation and comfort in non-uniform and dynamic environments. Building and Environment, 44(7), 1386-1391. https://doi.org/10.1016/j.buildenv.2008.04.006. 